\title{
QEEG Study on Reading Quranic Verse 36 'Yasin' and Malay Language
}

\author{
$1^{\text {st }}$ Norsiah Fauzan ${ }^{1}, 2^{\text {nd }}$ Muhammad Sophian Nazaruddin ${ }^{1}, 3^{\text {rd }}$ Ida Juliana Hutasuhut ${ }^{1}, 4^{\text {th }}$ \\ Ahmad Sofian Shminan ${ }^{1}, 5^{\text {th }}$ Merikan Aren ${ }^{1}, 6^{\text {th }}$ Syifaa Mohd. Sabri ${ }^{1}$ \\ \{fnorsiah@unimas.my ${ }^{1}$, msophian@unimas.my ${ }^{1}$, hijuliana@unimas.my ${ }^{1}$, sasofian@unimas.my ${ }^{1}$, \\ American@unimas.my ${ }^{1}$, syifaasabri107@gmail.com ${ }^{1}$ \} \\ Universiti Malaysia Sarawak, Faculty of Cognitive Science, Malaysia ${ }^{1}$
}

\begin{abstract}
This article reports the study on the brainwaves patterns between the activity of reading the Arabic and reading Malay text among the final year undergraduates in the university of Malaysia Sarawak. Three students volunteered for the research and their brain waves were observed and recorded to find out the difference of brainwave pattern while reading Arabic and Malay language. The observation showed a dominant production of delta followed by theta while reading Arabic and Malay language. The text used for reading were from Verse 36 (Arabic and the translated version in Malay) of the Quran. The average mean of delta wave were higher for the reading of Arabic language at the frontal lobe than while reading the Malay translation. The frequency of delta rhythm of the Arabic language differed from the Malay language due to the nature of the Arabic language. The neural circuits of the rhythm from the Arabic recitation implicates not on just the spatial visual area at the parietal lobe but also the visual eye movement at the frontal region guided by the Visual system at the Medial temporal area.
\end{abstract}

Keywords: EEG, Quran, Brain Waves, QEEG.

\section{Introduction}

The objective of this study is to observe the differences in the brainwaves patterns between the activity of reading the Arabic and reading Malay text among the Final Year students in University Malaysia Sarwak. QEEG is used as a tool for brain mapping. QEEG is an assessment tool that aids to measure and analyses the brain functions when the subject is engaged with the cognitive process [1]. QEEG was used to record the brainwave while analysing the brain response of participant towards the language use. Arabic is 186 million native speakers of the sixth spoken language in the world after Hindi, Mandarin, English, Spanish and Bengali Mandarin, English, Spainl and Bengali [2]

In of the previous research in Israel, Prof. Zohar Eviatar, Chair of the research team, said: "The characteristics of Arabic make it difficult for the right hemisphere to be involved. When you start something new, there are many of them [right hemisphere] [3]. In the research, 37 of Arabic speakers who aspoke English and Hebrew were involved. Professor Zohor Aviatar narrated that "The right hemisphere is more sensitive to the global aspects of what it's looking at, while the left hemisphere is more sensitive to the local features" [4]. As in previous research, this research The general objective of this research is to observe the differences in the brainwaves patterns between the subject reading the Arabic book and 
reading Malay book. Specifically, the objectives are to i. To identify all the brainwaves pattern and brain responses during both activity, reading Arabic book and reading Malay book, and to determine the dominant wave during the reading Arabic language and reading Malay language.

\section{Review of Literature}

\subsection{Quantitative Electroencephalogram}

Electroencephalogram or EEG is a machine that records the brain's electrical activity and is used clinically to detect aberrant activity such as epilepsy and sleep disorders. They are used to detect certain psychological states such as drowsiness and alertness because each of these states is associated with particular patterns of electrical activity. In electroencephalogram (EEG), the electrical signals consumed by the brain mind are written by metal pole and then position on the profiteer using a conductive gel then amplified. In order to prevent wrongly eye movement for brain activity, an electrode usually place near the eye muscles by the researcher which allows EEG signal occur as well as eye movement will be eliminated from time period for further analysis.

EEG were recorded using electrodes and arranged in a particular wave pattern. Brainwaves pattern can be detected using the international system 1020 in which a method that can determine the location of the scalp.

\subsection{Brain Waves}

Human brain consists of five common brainwaves which is delta, theta, alpha, beta and gamma. Theta brainwaves $(4-8 \mathrm{~Hz})$ are the second slowest magnitude brainwaves which can be represented a day-dream like and happened while we are in unconscious condition. Alpha brain waves $(8-12 \mathrm{~Hz}$ ) has slowe and large magnitude. Basically, alpha waves is related to a relaxation condition and our brain will undergo the process of brain shifting into an idling state, relaxed and disengaged with surrounding, slowly responded. The alpha waves increases when we close our eyes. Alpha activity is correlated with working memory and with longterm memory that can helps us to remember more the things around us. Beta brainwaves (above $13 \mathrm{~Hz}$ ) are small but faster brainwaves. It presents when we are at the state of alertness and engaged with focusing, memory retention activity. Gamma brainwaves $(13-100 \mathrm{~Hz})$ is the fastest of the brainwaves with high frequency. Gamma brainwaves occur when are doing perception and in a conscious state and it passes the information rapidly.

\subsection{Arabic vs Malay Language}

Arabic has twenty eight consonant letters and three of them is also use as long vowels. The root system is used in which four letters convey the basic idea of the word. For instance, the word "معلم" can mean teacher, tutor or professor. The diacritics determine the vowels. Different vowels used will produce different meaning to the root word and Arabic language consists of complete words and completer words [5]. The category of verbs, verbal nouns, adjectives and nouns are the example of complete words meanwhile pronoun, adverb, particles and exclamation words are the example of completer words. The Arabic language is written and read from right to left.

Malay is an Austronesian tongue. Most country in Asia like Malaysia, Indonesia, Singapore, Brunei and Thailand, use Malay language as their first language. During ancient 
time, the written Malay script was written in the Indian script. However, when English colonialist came to Malaya, the language had been changed to English language in both written and speaking using Latin alphabets. But, the script that called Jawi that consists all the twenty eight consonants. The similarity between Arabic and Malay language is that Malay language also has complete and completer words and the construction properties of position also consists of verbs, nouns, verbal nouns and adjectives. The Malay script is read.

\subsection{Previous Studies}

Previous study [6] claimed that meditation and classical music can help a person to be in relaxing condition. 14 subjects were chosen in this study and had performed two cognitive tasks, which was listening to Quran recitation and listening to hard music and they were measured by using EEG machine. The data was analysed by reading the EEG signal and the results showed that, by listening to Quran recitation, the brain are able generate the alpha wave and help a person always in calm condition compared to listening to hard rock music. The subjects were in the excitement condition and were not calmed while listening to hard music task as the result obtained shows that they have high value of beta wave compared to alpha wave. However, the subjects' who listened to Quran recitation, were in the calm situation with the increase of alpha wave value compared to beta. In a related study [7].

In this research, Arabic language used in the Quran was compared with the official Malay language to see if there is a difference in the brain physiological response. Ultimately, this research might work out on how best manage on strategies. In Arabic language, the meaning of the language might differ with the sounds and diacritical marks in contrast to the Malay language where the consonant and vowels are simply CVC VCVC or VCV. The vibration differs based on the phonological variation and vibration. The objectives of this study were to identify all the brainwaves pattern and brain responses during both activity, reading Arabic book and reading Malay book to determine the dominant wave during reading and Malay language.

\section{Methods}

This is a case study using Quantitative Electroencephalograph (QEEG) to observe the electrical activity of the brain while reading Arabic and the Malay language. This study involved two main tasks; reading Arabic language and reading Malay language. Electroencephalography (EEG) was used to observe the brainwave pattern while reading Arabic language and reading Malay language. Set of evident data of EEG were recorded from point during the performance of both readding Arabic language and reading Malay language.

\subsection{Subjects}

Three subjects involved in this study were volunteers aged from 19-26 years old from Faculty of Cognitive Science and Human Development. One of the main criteria for the research is the participants' ability of reading Arabic language. The briefing and inform consent were given to the participants before undergoing the session to ensure confidentiality of the data. The electrodes were placed based on the international 10/20 system. The artifacts such as noises and eyes blink were removed before the spectrum table and the bran topography were automatically generated $t$ for further analysis. 
The subjects were instructed to relax and also told to minimize their body movement to minimize the artefact, Four tasks were given; eyes open, eyes close. In the third condition, the subject started to read Arabic language and after three minutes of stabilization, the EEG data were recorded for 10 minutes. In this research, the researcher have chosen the "Ya seen" (verse 36) from the Al-Quran, which is very familiar to the muslim students and commonly read by other muslim in most of the occasion for healing and calming.

In the fourth task the subjects read the book after 6 minutes of stabilization. Same steps applied when reading in Arabic language, the data were taken for 10 minutes. after three minutes of stabilization Nineteen electrodes were placed on the scalp of the subjects based on the international standard, which is 10-20 system as follows: Fp1, Fp2, F7, F8, C3, C4, P3, P4, $\mathrm{O} 1, \mathrm{O} 2, \mathrm{~F} 7, \mathrm{~F} 8, \mathrm{~T} 3, \mathrm{~T} 4, \mathrm{~T} 5, \mathrm{~T} 6, \mathrm{Cz}, \mathrm{Pz}$, and then A1 and A2 mounted at the right and left ears of the subjects as references.

\section{Results and Discussion}

Microsoft word and the result were keyed in both SPSS and Microsoft Excel for further analysis. The average values and topographical maps were (Fig.2 and Fig.4 in appendix A) demonstrated to show the Regions of Interests (ROI) while reciting the Al Quran (Yassin) and Malay language.

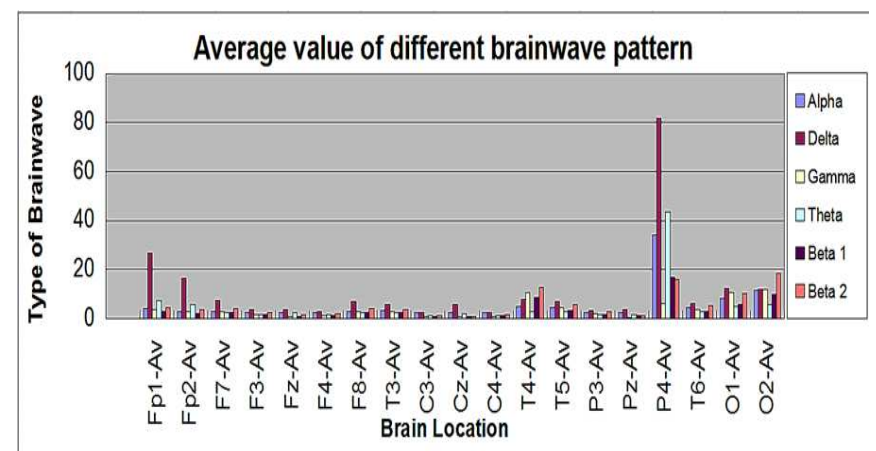

Figure 1. The graph of average value of all brainwave patterns in every location during Task 3 for all participants (Reading Arabic language) 


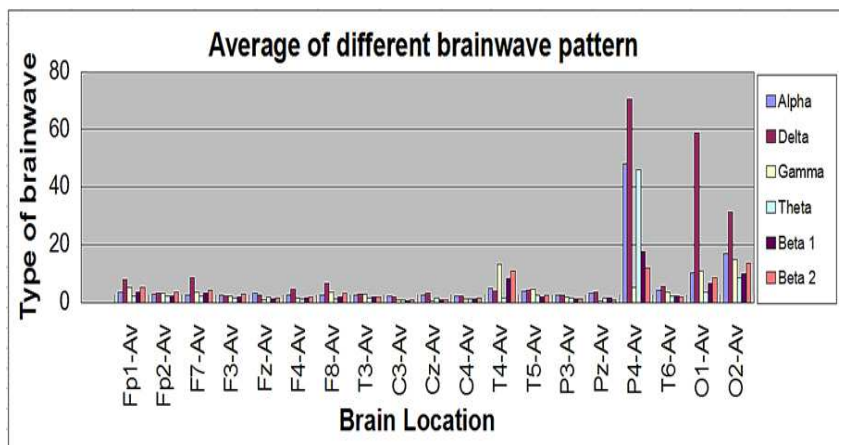

Figure 3. The graph of average value of all brainwave patterns in every location during Task 3 for all participants (Reading Malay language)

The mean value of delta was higher at frontal lobe (Fp2) during the reading of Arabic is higher compared to the reading of Malay language. The Mann-Whitney test was significant at 0.05. The main function of this area is to control important cognitive skills in humans, such as for memory, languages, and emotional expression.

Previous research shows that the delta wave is dominant at the frontal lobe because the main function of this area is to control important cognitive skills in humans, such as for memory, languages, emotional expression and it is the control panel for our personality and our ability to communicate. Thus, this proves that delta wave is dominant at the frontal lobe.

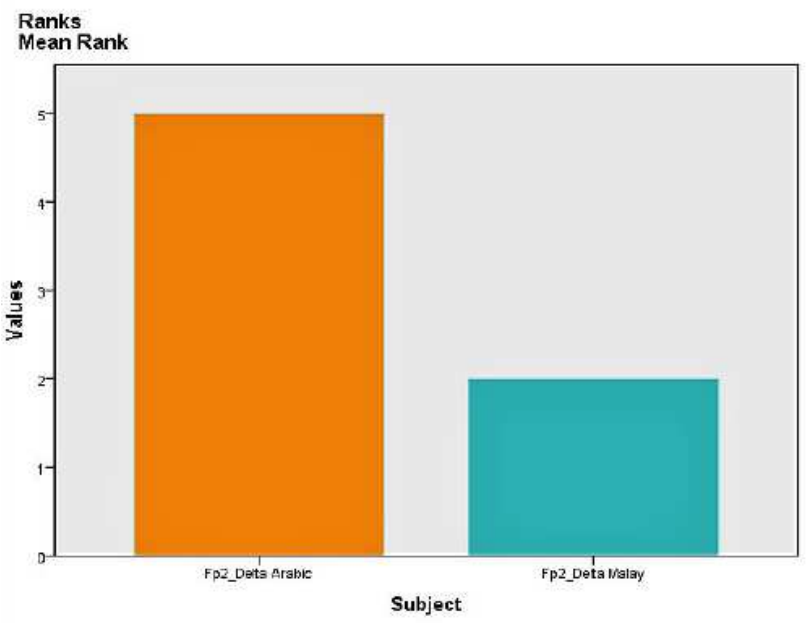

Figure 5. The mean value of Delta at the Frontal Lobe during Reading Malay and Arabic Language.

The findings showed that delta wave was dominant in both language (Arabic and Malay language) especially at the P4 (parietal area). However, delta dominated the frontal wave Fp2 during reading the Arabic language. The frontal lobe that consists of the executive function and anterior cingulate cortex is the most important area of the brain to perform the cognitive performance or decision making and judgement for the cognitive or psychological tasks. As 
indicated in the research by Professor Aviatar's team in Haifa, the area for discriminating the local features were left hemisphere In this case study.

The results of this study differed in terms of dominant wave from previous research $[8,9]$ where the recitation of the Quranic verse produced alpha waves and calming relaxation state. In their research, Quran recitation was higher compared to rest condition and listening slow and hard music. They conclude that Quran recitation produced a significant relaxation in which the Quran has an effect on some hormone and chemical responsible for relaxation. In this research, there was a dominant production of delta followed by theta. The recitation of AlQuran is natural sound that have unique characteristics and effects in human body [10].

There's a high possibility that production of delta implicated on the temporal region specifically the thalamus and corticothalamus area which is crucial for the healing and regeneration process. This is particularly related to the production of melatonin and suprachiamastic nucleus which consequently regulate the onset of sleep. The main difference between the Arabic and the reading of Malay language is the dominant delta wave rhythm at the frontal lobe. The frequency delta rhythm of the Arabic language differed from the Malay language due to the nature of the Arabic language. The neural circuits of the rhythm from the Arabic recitation implicates not on just the spatial visual area at the parietal lobe but also the visual eye movement guided by the Visual system at the Medial temporal area or Visual 5 system. The orthographical features of the Arabic writing required a fast movement or saccadic movement from right to left and the transmission of the visual feature from the various visual pathways has to be fast. Due to the deepest levels of relaxation that the delta brainwave provides, the body and mind are easily able to restore themselves after boosting your brain power.

More research should be done comparing the Arabic language and other languages such as Mandarin and Tamil to look at the impact of reading the language on parts of the brain such as Anterior coagulate cortex and temporal lobe. More participants should be included for reliability and generalization of data. The participants should be trained or screened for inclusion in the study. The ability to read based on the appropriate articulation of the Arabic language is important. For example, the pronounciation of the Arabic language might affect the phonological values of the sound and frequencies recorded by QEEG.

Acknowledgment. This work would not have been possible without the cooperation of the undergraduate students and facilities in term of equipment and laboratory in the Faculty of Cognitive science and Human Development.

\section{References}

[1] Kumlehn, M. (2011). Consumer Neuroscience: Pricing research to gain and sustain a cutting edge competitive advantage by improving customer value and profitability.

[2] Ager, A. and Strang, A. (2008) Understanding integration: a conceptual framework. Journal of Refugee Studies, Vol.21(2), pp.166-191.

[3] Katie Alcock (2010) Arabic 'hard for brain', BBC Mews, 10 September 2010 retrieved from http://www.bbc.co.uk/news/health-11181457Reading Arabic 'hard for brain'.

[4] Whitaker, B. (2008). The Arabic language. Retrieved July 27, 2008 from http://www.albab.com/arab/language/lang.htm. 
[5] Azian Azamimi Abdullah, Zainab Omar Azian Azamimi (2011) International Journal on Advanced Science engineering Bangi, Malaysia, 14-15 January 2011, DOI:10.18517/ijaseit.1.4.77.

[6] Mudhir S Sheka Abdullah O HassanSafin A.Othman (2013),Effects of Quran Listening and Music on Electroencephalogram brain waves, Egypt.J.Exp.Biol. (zoo), 2013; (1) 119-121.

[7] Noor Ashikin Zulkurnaini, Ros Shilawani S Abdul Kadir, Zunairah Hj Murat, Roshakimah Mohd Isa (2018) The comparison between listening to Al-Quran and listening to classical music on the brainwave signal for the alpha band retrieved on 20 June 2018 from :https://uitm.pure.elsevier.com/en/publications/.

\section{Appendix A. (Figure 2 and Figure 4)}

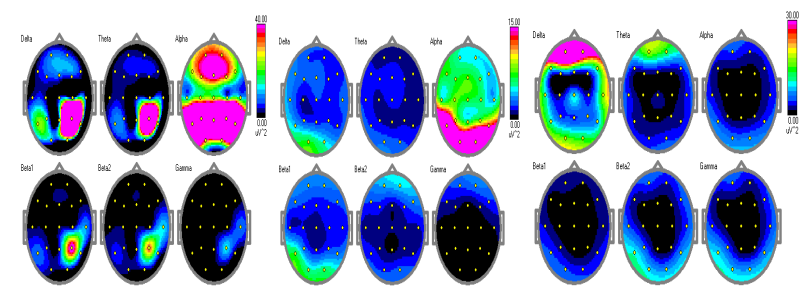

Figure 2. Brain Topography of all participants during Task 3 (reading Arabic language)

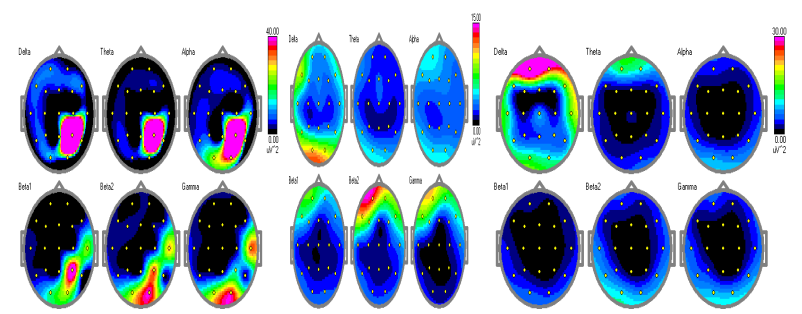

Figure 4. Brain topography of all participants during Task 4 (Reading Malay language) 